\title{
Structural Evidence that Propofol Stabilizes Different GABA Receptor States at Potentiating and Activating Concentrations
}

\author{
Daniel B. Williams, ${ }^{1,3}$ and Myles H. Akabas, ${ }^{1,2}$ \\ Departments of ${ }^{1}$ Physiology and Biophysics and ${ }^{2}$ Neuroscience, Albert Einstein College of Medicine, Bronx, New York 10461, \\ and 3Integrated Program in Cellular, Molecular, and Biophysical Studies, Columbia University, New York, New York 10032
}

The $\mathrm{GABA}_{\mathrm{A}}$ receptor is a target of many general anesthetics, such as propofol. General anesthetic binding sites are distinct from the GABA binding sites. At low concentrations, the anesthetics potentiate the currents induced by submaximal GABA concentrations. At higher concentrations the anesthetics directly activate $\mathrm{GABA}_{\mathrm{A}}$ receptors. In contrast, benzodiazepines, such as diazepam, only potentiate currents induced by submaximal GABA concentrations. Channel kinetic studies suggest that these drugs stabilize different receptor states. We previously showed that the accessibility of the anionic sulfhydryl reagent $p$-chloromercuribenzenesulfonate $\left(\mathrm{pCMBS}^{-}\right)$applied extracellularly to cysteines substituted for residues in the GABA $_{\mathrm{A}} \quad \alpha_{1}$ subunit M3 membrane-spanning segment was state-dependent. The subset of $\mathrm{pCMBS}^{-}$-accessible, M3 segment cysteine mutants acts as a reporter for receptor conformation. Here we show that $\mathrm{pCMBS}^{-}$, applied in the presence of a potentiating concentration of propofol, reacts with a subset

The GABA type $A\left(\mathrm{GABA}_{\mathrm{A}}\right)$ receptor is an allosteric inhibitory neurotransmitter-gated ion channel. The extracellular domain contains two GABA binding sites that when occupied induce channel opening and subsequent desensitization. The receptor also has binding sites for allosteric modulators, including some general anesthetics, benzodiazepines, and ethanol. The $\mathrm{GABA}_{\mathrm{A}}$ receptor is a target for the intravenous general anesthetic propofol, 2,6 di-isopropylphenol (Franks and Lieb, 1994; Krasowski and Harrison, 1999; Yamakura et al., 2001). At $\sim 0.5 \mu \mathrm{M}$, propofol potentiates currents induced by submaximal GABA concentrations but does not directly activate $\mathrm{GABA}_{\mathrm{A}}$ receptors. At 20 -fold higher concentrations, propofol directly activates receptors, causing channel opening in the absence of GABA (Sanna et al., 1995; Lam and Reynolds, 1998). Propofol does not bind at the GABA binding sites. It may bind in a crevice near the extracellular ends of the $\beta$ subunit M2 and M3 membrane-spanning segments (Jones et al., 1995; Krasowski et al., 1998). The effects of propofol on channel kinetics suggest that it stabilizes a doubly liganded,

\footnotetext{
Received March 20, 2002; revised April 23, 2002; accepted April 25, 2002.

This work was supported in part by National Institutes of Health Grants GM61925, NS30808, and GM63266. We thank Drs. Neil Harrison, Andrew Jenkins, and Jeffrey Horenstein for helpful discussions, Eric Goren for preparation of oocytes, and Drs. Moez Bali, Amal Bera, and Jeffrey Horenstein for comments on this manuscript.

Correspondence should be addressed to Dr. Myles Akabas, Department of Physiology and Biophysics, Albert Einstein College of Medicine, 1300 Morris Park Avenue, Bronx, NY 10461. E-mail: makabas@aecom.yu.edu.

D. B. Williams' present address: Laboratory for Molecular Neuropharmacology, National Institute of Neurological Disorders and Stroke, National Institutes of Health, Building 10, Room 5C103, 10 Center Drive, Bethesda, MD 20892. Copyright (C) 2002 Society for Neuroscience $0270-6474 / 02 / 227417-08 \$ 15.00 / 0$
}

of $\alpha_{1}$ subunit, M3 segment, cysteine-substitution mutants (Y294C, V297C, I302C, F304C). In the presence of a directly activating concentration of propofol $\mathrm{pCMBS}^{-}$reacts with a different subset of the M3 cysteine-substitution mutants (Y294C, S299C, I302C, E303C, A305C). These subsets are distinct from the subsets of $\mathrm{M} 3$ cysteine-substitution mutants that are reactive with $\mathrm{pCMBS}^{-}$in the absence and presence of GABA and in the presence of diazepam. We hypothesize that distinct subsets of reactive residues represent distinct conformations or ensembles of conformations of the receptor. These results provide structural evidence for at least five distinct receptor states, three nonconducting states, resting, diazepam-bound and potentiating propofol-bound, and two conducting-desensitized states, the activating propofol-bound and GABA-bound states.

Key words: acetylcholine; glycine; anesthesia; benzodiazepine; isoflurane; ethanol

pre-open, nonconducting state (Bai et al., 1999). Little is known, however, about the structure of the propofol-bound receptor and how it differs from the resting state structure.

We previously showed that the reactivity of cysteines substituted for $\alpha_{1}$ M3 membrane-spanning segment residues with pC$\mathrm{MBS}^{-}$applied extracellularly is state-dependent. The subset of $\mathrm{pCMBS}^{-}$-reactive residues provides a reporter for the receptor state (Williams and Akabas, 1999). In the resting state $\mathrm{pCMBS}^{-}$ only reacted with cysteine (Cys) substituted for $\alpha_{1}$ Ala291 and $\alpha_{1}$ Tyr294, residues near the extracellular end of M3. In the presence of GABA, $\mathrm{pCMBS}^{-}$reacted with Cys substituted for five more M3 residues $\left(\alpha_{1} \mathrm{~F} 296 \mathrm{C}, \alpha_{1} \mathrm{~F} 298 \mathrm{C}, \alpha_{1} \mathrm{~A} 300 \mathrm{C}, \alpha_{1} \mathrm{~L} 301 \mathrm{C}\right.$, and $\alpha_{1}$ E303C). Diazepam, a benzodiazepine, potentiates currents induced by submaximal GABA concentrations but does not directly activate $\mathrm{GABA}_{\mathrm{A}}$ receptors. When $\mathrm{pCMBS}^{-}$was applied with diazepam, it reacted with a subset of the M3 Cys-substitution mutants ( $\alpha_{1} \mathrm{~A} 291 \mathrm{C}, \alpha_{1} \mathrm{Y} 294 \mathrm{C}, \alpha_{1} \mathrm{~F} 296 \mathrm{C}, \alpha_{1} \mathrm{~F} 298 \mathrm{C}$, and $\left.\alpha_{1} \mathrm{~L} 301 \mathrm{C}\right)$ that were accessible in the presence of GABA (Williams and Akabas, 2000, 2001). We inferred that diazepam binding induced or stabilized a distinct conformation or ensemble of receptor conformations. Kinetic studies suggest this may be a singly liganded state (Rogers et al., 1994; Lavoie and Twyman, 1996).

Although both diazepam and propofol potentiate GABA currents, they have different effects on $\mathrm{GABA}_{\mathrm{A}}$ receptor kinetics (Rogers et al., 1994; Bai et al., 1999; Ghansah and Weiss, 1999; O'Shea et al., 2000). This implies that they stabilize different states or ensembles of states. We hypothesized that the pattern of $\mathrm{pCMBS}^{-}$-reactive M3 Cys residues is a marker for different states. Therefore, to provide structural evidence that propofol 
stabilizes specific states, we investigated the effect of coapplying $\mathrm{pCMBS}^{-}$with either potentiating or directly activating concentrations of propofol on the $\alpha_{1}$ M3 segment Cys-substitution mutants. Our results indicate that different subsets of M3 Cys mutants reacted with $\mathrm{pCMBS}^{-}$applied in the presence of potentiating and directly activating concentrations of propofol. The reactive Cys mutants were distinct from those that reacted in the resting, GABA-bound and diazepam-bound states. We conclude that propofol stabilizes a specific receptor conformation or conformations.

\section{MATERIALS AND METHODS}

Mutants and expression. The rat $\alpha_{1} \mathrm{M} 3$ segment cysteine-substitution mutants in the pGEMHE plasmid were generated and characterized previously (Williams and Akabas, 1999). In vitro mRNA transcription and Xenopus oocyte preparation and injection were as described previously (Xu and Akabas, 1993; Williams and Akabas, 1999). Oocytes were injected with $50 \mathrm{nl}$ of a $200 \mathrm{pg} / \mathrm{nl}$ solution of subunit mRNA in a 1:1:1 ratio of $\alpha_{1}: \beta_{1}: \gamma_{2 s}$.

Electrophysiology. Two-electrode voltage-clamp recording from Xenopus oocytes and data acquisition and analysis were performed as described previously (Xu and Akabas, 1996; Williams and Akabas, 1999). Oocytes were continuously perfused at $5 \mathrm{ml} / \mathrm{min}$ with calcium-free frog Ringer's (CFFR) (in mM: $115 \mathrm{NaCl}, 2.5 \mathrm{KCl}, 1.8 \mathrm{MgCl}_{2}$, and $10 \mathrm{HEPES}$, $\mathrm{pH} 7.5$, with $\mathrm{NaOH}$ ) at room temperature. Oocyte recording chamber volume was $\sim 250 \mu$ l. Holding potential was $-80 \mathrm{mV}$.

Experimental protocols. The sulfhydryl specific reagent used in these experiments was $p$-chloromercuribenzenesulfonate $\left(\mathrm{pCMBS}^{-}\right)$(Sigma, St. Louis, MO). After reaction with pCMBS ${ }^{-},-\mathrm{HgC}_{6} \mathrm{H}_{4} \mathrm{SO}_{3}{ }^{-}$is covalently coupled to the reactive sulfhydryl.

To determine the irreversible effects of $\mathrm{pCMBS}^{-}$on the GABAinduced currents, the following series of reagents were applied to twoelectrode voltage-clamped oocytes: $100 \mu \mathrm{M}$ GABA, $20 \mathrm{sec} ; 100 \mu \mathrm{M}$ GABA, 20 sec; $E_{50}$ GABA, 20 sec; propofol alone, 20 sec; propofol + $\mathrm{EC}_{50}$ GABA, $20 \mathrm{sec} ; \mathrm{EC}_{50}$ GABA, $20 \mathrm{sec} ; 0.5 \mathrm{~mm} \mathrm{pCMBS}{ }^{-} \pm$propofol, (for propofol concentration and duration of application see below); 100 $\mu \mathrm{M}$ GABA, $20 \mathrm{sec} ; 100 \mu \mathrm{M}$ GABA, $20 \mathrm{sec} ; \mathrm{EC}_{50}$ GABA, $20 \mathrm{sec} ; \mathrm{EC}_{50}$ GABA, $20 \mathrm{sec}$ (see Figs. 1 and 2 for examples). The applications of GABA and reagents were separated by $3-5$ min washes with CFFR to allow complete recovery from desensitization. For wild-type and each Cys mutant, propofol was applied at two concentrations; one that caused potentiation but no detectable direct activation, and at $50 \mu \mathrm{M}$ propofol, a concentration that caused direct activation in all mutants. The potentiating concentration of propofol used was $0.5 \mu \mathrm{M}$ for all mutants except V297C where $0.1 \mu \mathrm{M}$ propofol was used because direct activation was observed with $0.5 \mu \mathrm{M}$ propofol. To avoid accumulation of propofol in the oocyte membranes and potentiation of subsequent GABA-induced currents, we applied $\mathrm{pCMBS}^{-}$in the presence of the potentiating propofol concentration as three $20 \mathrm{sec}$ applications interspersed by CFFR washes for a total of $1 \mathrm{~min}$ of $\mathrm{pCMBS}^{-}$application. For the directly activating propofol concentration, as discussed more extensively in Results, we could not avoid accumulation of propofol in the oocyte membranes and potentiation of subsequent GABA-induced currents so we simply applied $\mathrm{pCMBS}^{-}$for $1 \mathrm{~min}$ in the presence of activating propofol. Stock solutions of propofol in DMSO were diluted into CFFR immediately before application. The percentage of DMSO was never $>0.02 \%$ and had no effect on GABA-induced current (data not shown).

We infer that an irreversible change in the GABA-induced currents after $\mathrm{pCMBS}^{-}$application is attributable to the covalent modification of a Cys by pCMBS ${ }^{-}$. Whether the change is potentiation or inhibition of subsequent GABA-induced currents does not affect this conclusion. At any given position Cys modification by $\mathrm{pCMBS}^{-}$may alter ion conduction or gating kinetics. Potentiation after $\mathrm{pCMBS}^{-}$modification is almost certainly caused by a change in gating kinetics manifested as a reduction in the $\mathrm{GABA} \mathrm{EC}_{50}$. We have not examined the mechanistic basis for the effects of $\mathrm{pCMBS}^{-}$modification in this paper because it is not relevant to the major focus of this investigation. The percent effect of $\mathrm{pCMBS}^{-}=\left\{\left(I_{\mathrm{GABA}}\right.\right.$, after $/ I_{\mathrm{GABA}}$, before $\left.)-1\right\} * 100 . I_{\mathrm{GABA}}$, after is the average peak current of the two GABA test pulses after the application of $\mathrm{pCMBS}^{-}$, and $I_{\mathrm{GABA}}$, before is the average of the peak current of the initial two GABA applications. Test pulses of GABA were applied at two concentrations, $\mathrm{EC}_{50}$ and $>5$ times $\mathrm{EC}_{50}$ (near-saturating GABA, generally $100 \mu \mathrm{M}$ except for L301C where $1 \mathrm{~mm}$ was used). Changes in the peak
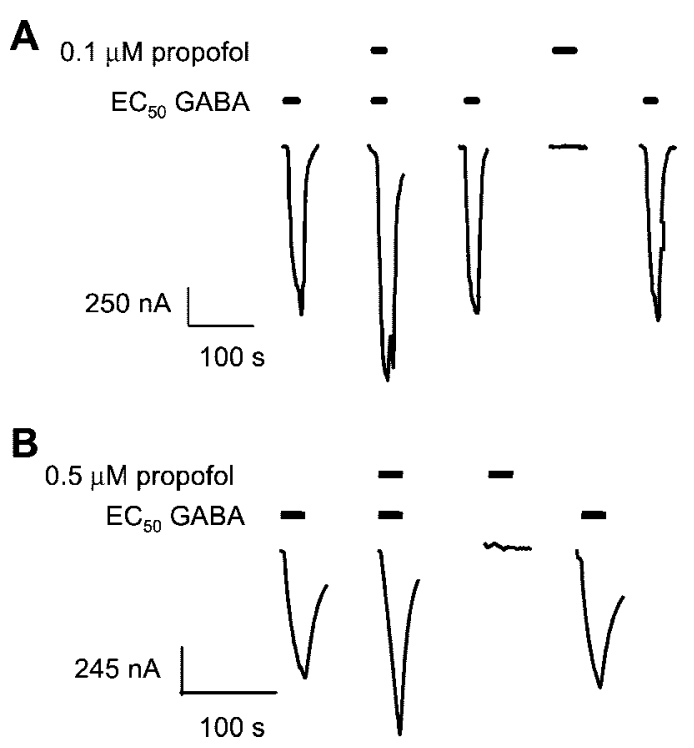

Figure 1. Low concentrations of propofol potentiate GABA-induced currents but do not directly activate the receptors. Effects of propofol application on the currents recorded by two-electrode voltage clamp from oocytes expressing the $\alpha_{1}$ V297C $(A)$ and $\alpha_{1}$ L301C $(B)$ mutants. Bars above the current traces indicate the reagent applied and the duration of application. Time between current traces is $3-5$ min. Holding potential, $-80 \mathrm{mV}$. Note that propofol potentiates the GABA-induced currents but does not elicit a current when applied by itself at these concentrations. Also, the propofol effects wash out so that the final GABA test current is similar to the initial current.
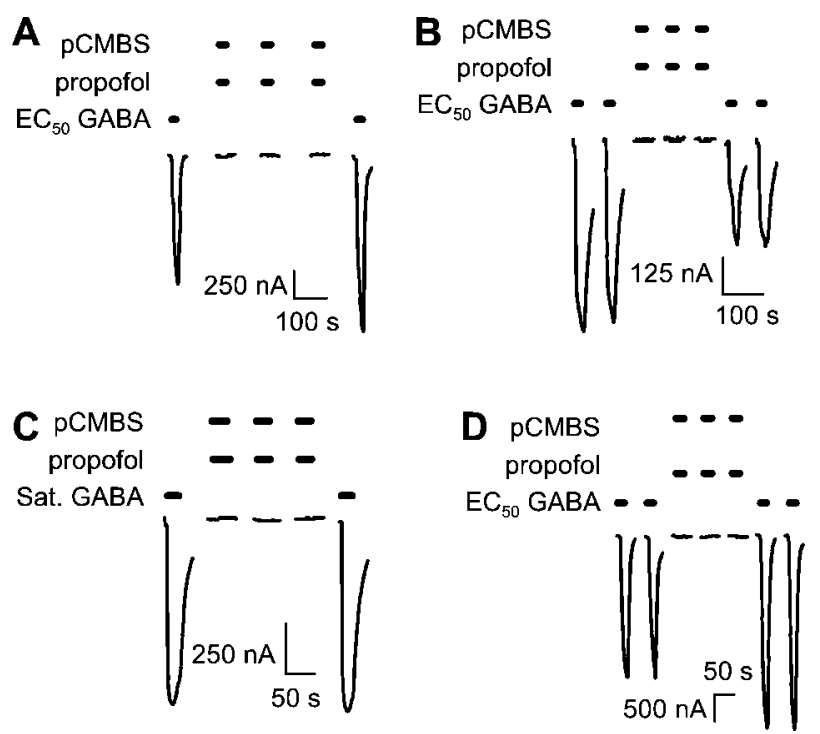

Figure 2. The effect of coapplication of $0.5 \mathrm{~mm} \mathrm{pCMBS}^{-}$with a potentiating concentration of propofol on the subsequent GABA-induced currents. Currents recorded by two-electrode voltage clamp from oocytes expressing the $\alpha_{1} \mathrm{~V} 297 \mathrm{C}(A), \alpha_{1} \mathrm{I} 302 \mathrm{C}(B), \alpha_{1} \mathrm{E} 303 \mathrm{C}(C)$, and $\alpha_{1} \mathrm{~F} 304 \mathrm{C}$ $(D)$ mutants. Bars above the current traces indicate the reagent applied and the duration of application. Time between current traces is 3-5 min. Holding potential, $-80 \mathrm{mV}$. The propofol concentration was $0.1 \mu \mathrm{M}$ in $A$ and $0.5 \mu \mathrm{M}$ in $B-D$. Note that in $A$ and $D$ the subsequent GABA-induced currents were potentiated; in $B$ the subsequent currents were inhibited, and in $B-D$ the subsequent currents were unchanged.

current induced by the $\mathrm{EC}_{50}$ GABA test pulses are more sensitive to effects of $\mathrm{pCMBS}^{-}$modification on gating kinetics, whereas changes in the peak current induced by the near-saturating GABA test pulses are more sensitive to effects of modification on conductance (Williams and Akabas, 1999). 
For screening experiments, $\mathrm{pCMBS}^{-}$was applied for $1 \mathrm{~min}$ at $0.5 \mathrm{~mm}$. This combination of time and concentration were chosen because they were the maximal concentration and duration that caused no significant increase in the leak conductance of uninjected Xenopus oocytes. This limits our ability to detect reactive residues. As discussed below, for a given mutant, given the variability of responses, application of a reagent must cause a net change in current greater than $\sim 30 \%$ to be statistically significantly different than wild type by a one-way ANOVA (for $n$ between 4 and 6). Thus, if complete reaction caused $100 \%$ inhibition of the GABA-induced current, with a detection threshold of $30 \%$ effect and the $\mathrm{pCMBS}^{-}$reaction conditions of $0.5 \mathrm{~mm}$ applied for $1 \mathrm{~min}$, the slowest reaction rate that we can detect must have a second order reaction rate constant $>121 \cdot \mathrm{mol}^{-1} \cdot \mathrm{sec}^{-1}$.

Measurement of reaction rates. $\mathrm{pCMBS}^{-}$reaction rates with the engineered Cys were determined by the effect of sequential brief applications of $\mathrm{pCMBS}^{-}$as we have done previously (Williams and Akabas, 1999, 2000). A test pulse of GABA was applied to measure the GABA-induced current. Propofol $+\mathrm{pCMBS}^{-}(0.2-0.5 \mathrm{mM})$ was applied for $15-60 \mathrm{sec}$. After washout, a test pulse of GABA was applied, and the GABAinduced current was measured. The effect of five to eight brief, sequential applications of propofol $+\mathrm{pCMBS}^{-}$were determined. The magnitudes of the GABA test currents were normalized relative to the initial test current. The normalized current was plotted as a function of the cumulative duration of $\mathrm{pCMBS}^{-}$application and fitted with a single exponential function using Prism2 software (GraphPad, San Diego, CA). The second order rate constant was calculated by dividing the pseudo-first order rate constant obtained from the exponential fit by the pCMBS concentration.

Statistics and curve fitting. Data are expressed as the percentage change of current after modification \pm SEM. The significance of differences between each mutant and wild type was determined by one-way ANOVA using the Student-Newman-Keuls post hoc test (SPSS for Windows; SPSS, Inc., Chicago, IL). Dose-response curves were fit using Prism2 software.

It is important to recognize that $\mathrm{pCMBS}^{-}$-reactive residues were identified based on the functional effect of modification. Functional effects were determined by the statistical significance of the effect on a mutant relative to the effect on wild type. For mutants where the average effect after application of pCMBS $^{-}$was small, whether the effect was judged to be significant depended, in part, on the stringency of the one-way ANOVA post hoc test used. In our previous work on the $\alpha_{1} \mathrm{M} 3$ segment, using the Student-Newman-Keuls post hoc test to determine significance of effects, the effect of $\mathrm{pCMBS}^{-}$applied in the presence of GABA was statistically significant at six residues, $\alpha_{1}$ A291C, $\alpha_{1}$ Y294C, $\alpha_{1} \mathrm{~F} 298 \mathrm{C}, \alpha_{1} \mathrm{~A} 300 \mathrm{C}, \alpha_{1} \mathrm{~L} 301 \mathrm{C}$, and $\alpha_{1} \mathrm{E} 303 \mathrm{C}$. With the less stringent Duncan post hoc test, an additional residue $\alpha_{1} \mathrm{~F} 296 \mathrm{C}$ is judged to be reactive with $\mathrm{pCMBS}^{-}$applied in the presence of GABA (Williams and Akabas, 1999). The choice of post hoc test is, unfortunately, somewhat arbitrary. Thus, for Cys mutants where the effects of complete reaction are small, it may be difficult to determine functionally whether reaction has occurred.

\section{RESULTS}

\section{Characterization of propofol effects on the M3 Cys mutants}

The GABA $\mathrm{EC}_{50}$ for wild-type $\alpha_{1} \beta_{1} \gamma_{2 \mathrm{~S}}$ receptors was $2.1 \pm 1.3$ $\mu \mathrm{M}(n=6)$ and for the Cys-substitution mutants ranged between $0.5 \pm 0.1 \mu \mathrm{M}$ for $\alpha_{1} \mathrm{~A} 291 \mathrm{C}$ and $\alpha_{1} \mathrm{Y} 294 \mathrm{C}$ and $48 \pm 15 \mu \mathrm{M}$ for $\alpha_{1} \mathrm{~L} 301 \mathrm{C}$, as reported previously (Williams and Akabas, 1999). Lacking a high-resolution structure of the membrane-spanning domain, it is difficult to infer the structural basis for the changes in $\mathrm{GABA} \mathrm{EC}_{50}$ that resulted from Cys substitutions. Either the mutations subtly alter the structure of the M3 segment or during gating induced conformational changes the environment of these Cys residue changes. Either way these changes somehow affect the kinetics of the transitions or the relative stability of different receptor states thereby altering the $\mathrm{GABA} \mathrm{EC}_{50}$. For an extensive discussion of the relationship between mutations and $\mathrm{EC}_{50}$, see (Colquhoun, 1998).

For each Cys mutant, propofol dose-response relationships were determined to identify the maximum propofol concentra-
Table 1. Extent of potentiation and direct activation of the $\alpha_{1}$ M3 Cys substitution mutants by propofol

\begin{tabular}{lcc} 
Mutant & $\begin{array}{c}\text { Percentage of } \\
\text { potentiation }^{a}\end{array}$ & $\begin{array}{c}\text { Percentage of } \\
\text { direct activation }\end{array}$ \\
\hline V292C & $13 \pm 4(4)$ & $26 \pm 5(3)$ \\
C293, WT & $46 \pm 12(7)$ & $41 \pm 5(5)$ \\
Y294C & $102 \pm 46(3)$ & $65 \pm 8(3)$ \\
A295C & $28 \pm 14(3)$ & $24 \pm 7(6)$ \\
F296C & $71 \pm 20(3)$ & $33 \pm 11(4)$ \\
V297C & $57 \pm 15(5)$ & $50 \pm 7(6)$ \\
F298C & $22 \pm 5(4)$ & $49 \pm 7(4)$ \\
S299C & $13 \pm 5(3)$ & $88 \pm 3(4)$ \\
A300C & $34 \pm 4(4)$ & $146 \pm 20(10)$ \\
L301C & $51 \pm 5(3)$ & $57 \pm 6(3)$ \\
I302C & $27 \pm 16(4)$ & $25 \pm 11(4)$ \\
E303C & $40 \pm 6(6)$ & $63 \pm 5(6)$ \\
F304C & $43 \pm 11(3)$ & $65 \pm 4(3)$ \\
A305C & $42 \pm 12(5)$ & $51 \pm 7(4)$ \\
T306C & $39 \pm 20(4)$ & $85 \pm 6(5)$ \\
V307C & $33 \pm 9(6)$ & $41 \pm 2(4)$
\end{tabular}

$\overline{{ }^{a}}$ The percentage of potentiation was $\left\{\left(I_{\mathrm{GABA}}+\text { Propofol } / I_{\mathrm{GABA}}\right)-1\right\}^{*} 100$. Propofol $(0.5 \mu \mathrm{M})$ was used for all mutants except V297C, where $0.1 \mu \mathrm{M}$ propofol was used. $\mathrm{EC}_{50}$ GABA concentration was used. Mean \pm SEM is given. Number of oocytes is indicated in parentheses.

${ }^{b}$ The percentage of direct activation was calculated as $\left\{\left(I_{\text {Propofol }} / I_{\mathrm{GABA}}\right)-1\right\} * 100$. The propofol concentration was $50 \mu \mathrm{M}$ in all cases. The GABA concentration was $100 \mu \mathrm{M}$.

tion that potentiated GABA-induced currents without directly activating the receptors. For most Cys mutants the concentration used was $0.5 \mu \mathrm{M}$. A $0.5 \mu \mathrm{M}$ concentration of propofol potentiated $\mathrm{EC}_{20}$ to $\mathrm{EC}_{50} \mathrm{GABA}$ currents in wild-type receptors by $46 \pm 12 \%$ $(n=7)$ and in the mutants potentiation ranged from $13 \%$ for $\alpha_{1} \mathrm{~V} 292 \mathrm{C}$ and $\alpha_{1} \mathrm{~S} 299 \mathrm{C}$ to $102 \%$ for $\alpha_{1} \mathrm{Y} 294 \mathrm{C}$ (Table 1 ). For $\alpha_{1} \mathrm{~V} 297 \mathrm{C}$, direct activation occurred at $0.5 \mu \mathrm{M}$, and so $0.1 \mu \mathrm{M}$ propofol was used. The effects of application of potentiating concentrations of propofol washed out completely within $5 \mathrm{~min}$. It is difficult to establish an $\mathrm{EC}_{50}$ for propofol potentiation because as the propofol concentration increases, potentiation effects run into direct activation, making it difficult to determine the maximum potentiation. At propofol concentrations $>50 \mu \mathrm{M}$ the direct activation current declines suggesting an inhibitory effect at high propofol concentrations. The mechanism of this inhibition is unknown.

All of the Cys mutants showed direct activation by $50 \mu \mathrm{M}$ propofol. For wild-type receptors, the current induced by $50 \mu \mathrm{M}$ propofol was $41 \pm 5 \%(n=5)$ of the current induced by saturating GABA. For the Cys mutants, the current induced by $50 \mu \mathrm{M}$ propofol relative to the maximal GABA-induced current ranged from $24 \%$ for $\alpha_{1} \mathrm{~A} 295 \mathrm{C}$ to $146 \%$ for $\alpha_{1} \mathrm{~A} 300 \mathrm{C}$ (Table 1 ). Washout of $50 \mu \mathrm{M}$ propofol terminated the propofol-induced currents in all mutants, however, subsequent GABA-induced currents were potentiated relative to the initial GABA test currents for over 30 min after propofol washout. Addition of $10 \mathrm{mg} / \mathrm{ml}$ bovine serum albumin to the wash buffer did not speed the washout of this propofol-induced potentiation of subsequent GABA-induced currents. This limited our ability to detect Cys mutants as reactive with $\mathrm{pCMBS}^{-}$plus $50 \mu \mathrm{M}$ propofol to those mutants where the effect on subsequent currents was inhibition. Because of the very slow washout of propofol from the oocyte membranes and the persistent potentiation of subsequent GABA currents, we were unable to identify as reactive in the presence of activating con- 


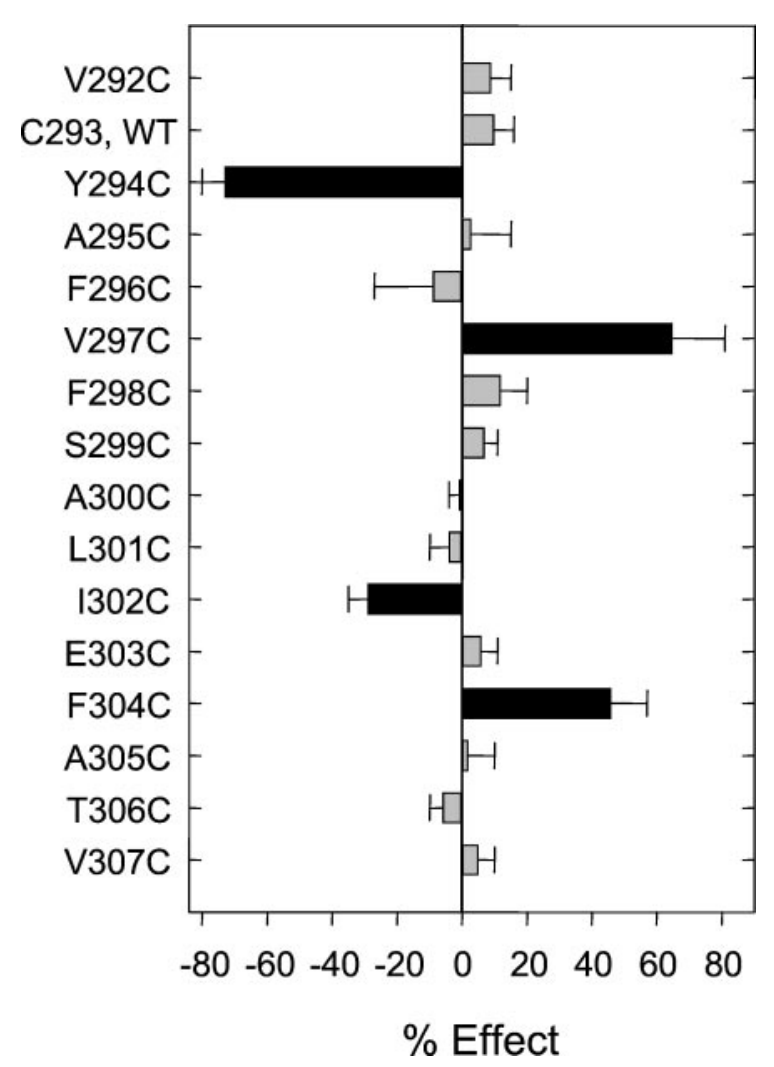

Figure 3. The irreversible effect of a $1 \mathrm{~min}$ application of $0.5 \mathrm{~mm}$ pCMBS $^{-}$applied in the presence of a potentiating concentration of propofol on subsequent GABA-induced currents of wild-type and mutant $\mathrm{GABA}_{\mathrm{A}}$ receptors. For each mutant an $\mathrm{EC}_{50}$ GABA concentration was used for the test pulses. Black bars indicate effects that are statistically significantly different from the effect on wild type by a one-way ANOVA. A negative effect indicates inhibition, and a positive effect indicates potentiation of subsequent GABA currents. The mean and SEM values are shown. For each mutant, the effects on three to six oocytes are averaged.

centrations of propofol any position where the effect of $\mathrm{pCMBS}^{-}$ modification was potentiation.

\section{Reactions with $\mathrm{pCMBS}^{-}$applied in the presence of potentiating concentrations of propofol}

For wild type and all of the M3 Cys mutants, the effects of a 1 min application of a potentiating concentration of propofol washed out after a 5 min wash with CFFR buffer (Fig. 1). A $1 \mathrm{~min}$ application of $0.5 \mathrm{mM} \mathrm{pCMBS}^{-}$with a potentiating concentration of propofol had no effect on wild-type $\alpha_{1} \beta_{1} \gamma_{2 \mathrm{~s}}$ receptors (Williams and Akabas, 1999). When applied for $1 \mathrm{~min}$ in the presence of a potentiating concentration of propofol, $\mathrm{pCMBS}^{-}$irreversibly altered the subsequent GABA-induced currents of the mutants $\alpha_{1}$ Y294C, $\alpha_{1}$ V297C, $\alpha_{1}$ I302C, and $\alpha_{1}$ F304C (Figs. 2, 3). The subsequent currents were inhibited for the mutants $\alpha_{1} \mathrm{Y} 294 \mathrm{C}$ and $\alpha_{1} \mathrm{I} 302 \mathrm{C}$. The subsequent currents were potentiated for the mutants $\alpha_{1}$ V297C and $\alpha_{1}$ F304C (Figs. 2, 3). $\alpha_{1}$ Y294C reacts with $\mathrm{pCMBS}^{-}$in the resting state, thus, to determine whether propofol altered the reactivity of $\alpha_{1}$ Y294C, we measured the rate of reaction in the presence and in the absence of propofol. In the presence of propofol the second order reaction rate constant for $\mathrm{pCMBS}^{-}$with $\alpha_{1} \mathrm{Y} 294 \mathrm{C}$ was $134 \pm 201 \cdot \mathrm{mol}^{-1} \cdot \mathrm{sec}^{-1}(n=3)$. In the resting state the second order rate constant was $47 \pm 8$ $1 \cdot \mathrm{mol}^{-1} \cdot \mathrm{sec}^{-1}$, and in the presence of GABA the rate constant was $86 \pm 14 \mathrm{l} \cdot \mathrm{mol}^{-1} \cdot \mathrm{sec}^{-1}$ (Williams and Akabas, 1999). The

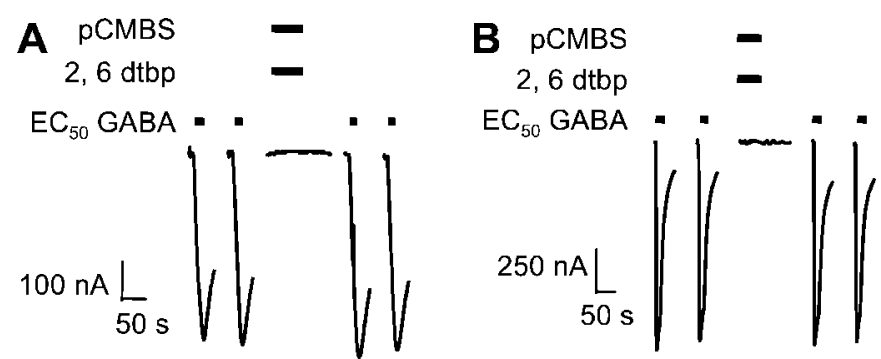

Figure 4. The lack of effect of a 1 min application of $0.5 \mathrm{mM} \mathrm{pCMBS}^{-}$ applied in the presence of 2,6 di-tert-butyl-phenol (2,6 dtbp), a nonanesthetic analog of propofol, on GABA-induced currents from oocytes expressing $\alpha_{1} \mathrm{~V} 297 \mathrm{C}(A)$ and $\alpha_{1} \mathrm{~A} 305 \mathrm{C}(B)$. The concentration of 2,6 di-tert-butyl-phenol was similar to a potentiating propofol concentration, $0.5 \mu \mathrm{M}$ in $A$, and similar to an activating propofol concentration, $50 \mu \mathrm{M}$ in $B$. Time between current traces is $3-5 \mathrm{~min}$. Holding potential, $-80 \mathrm{mV}$. Note that the initial and final GABA currents are similar.

increased reaction rate in the presence of a potentiating concentration of propofol implies that propofol altered the environment and/or the access pathway to this residue compared with the resting and GABA-activated states.

The compound 2,6-di-tert-butylphenol is structurally similar to propofol but is not an anesthetic (Krasowski et al., 2001). To determine the specificity of propofol, we applied $\mathrm{pCMBS}^{-}$with 2,6-di-tert-butylphenol at the same concentration as propofol on the reactive mutants. There was no effect of a 1 min application of 2,6-di-tert-butylphenol plus $0.5 \mathrm{mM} \mathrm{pCMBS}^{-}$on any of the four Cys mutants that reacted with $\mathrm{pCMBS}^{-}$in the presence of propofol (Fig. 4). This suggests that the propofol-induced changes in M3 Cys mutant reactivity may be related to the anesthetic activity of propofol and not simply caused by its hydrophobicity.

\section{Reactions with $\mathrm{pCMBS}^{-}$applied in the presence of a directly activating concentration of propofol}

A 1 min application of $50 \mu \mathrm{M}$ propofol to wild-type $\alpha_{1} \beta_{1} \gamma_{2 \mathrm{~S}}$ receptors resulted in potentiation of subsequent submaximal GABA-induced test currents but had no effect on currents elicited by saturating concentrations of GABA. Although the extent of this potentiation of submaximal GABA-induced test currents diminished over time, it was still significant after $30 \mathrm{~min}$ of washing. Similar effects were observed with all of the mutants. We assume that during the $50 \mu \mathrm{M}$ propofol application, it partitioned into the oocyte membranes and then gradually leached out leaving a concentration sufficient to potentiate subsequent submaximal GABA responses, but not sufficient to directly activate. This limited our ability to detect Cys mutants that were reactive with $\mathrm{pCMBS}^{-}$plus $50 \mu \mathrm{M}$ propofol because we could only use saturating GABA test pulses. Thus, only at Cys mutants where $\mathrm{pCMBS}^{-}$application inhibited subsequent GABA-induced currents can we infer that reaction has occurred. If $\mathrm{pCMBS}^{-}$reaction potentiated subsequent GABA-induced currents, an effect that we would only expect to see with submaximal GABA test pulse, it would be difficult for us to distinguish the effect from the persistent potentiation because of slow washout of the propofol. Thus, all of the experiments with a directly activating propofol concentration used only saturating concentrations of GABA test pulses.

For wild-type $\alpha_{1} \beta_{1} \gamma_{2 \mathrm{~S}}$ receptors, a $1 \mathrm{~min}$ application of $0.5 \mathrm{~mm}$ $\mathrm{pCMBS}^{-}$with $50 \mu \mathrm{M}$ propofol had no subsequent inhibitory effect. When applied for $1 \mathrm{~min}$ in the presence of $50 \mu \mathrm{M}$ propofol, 

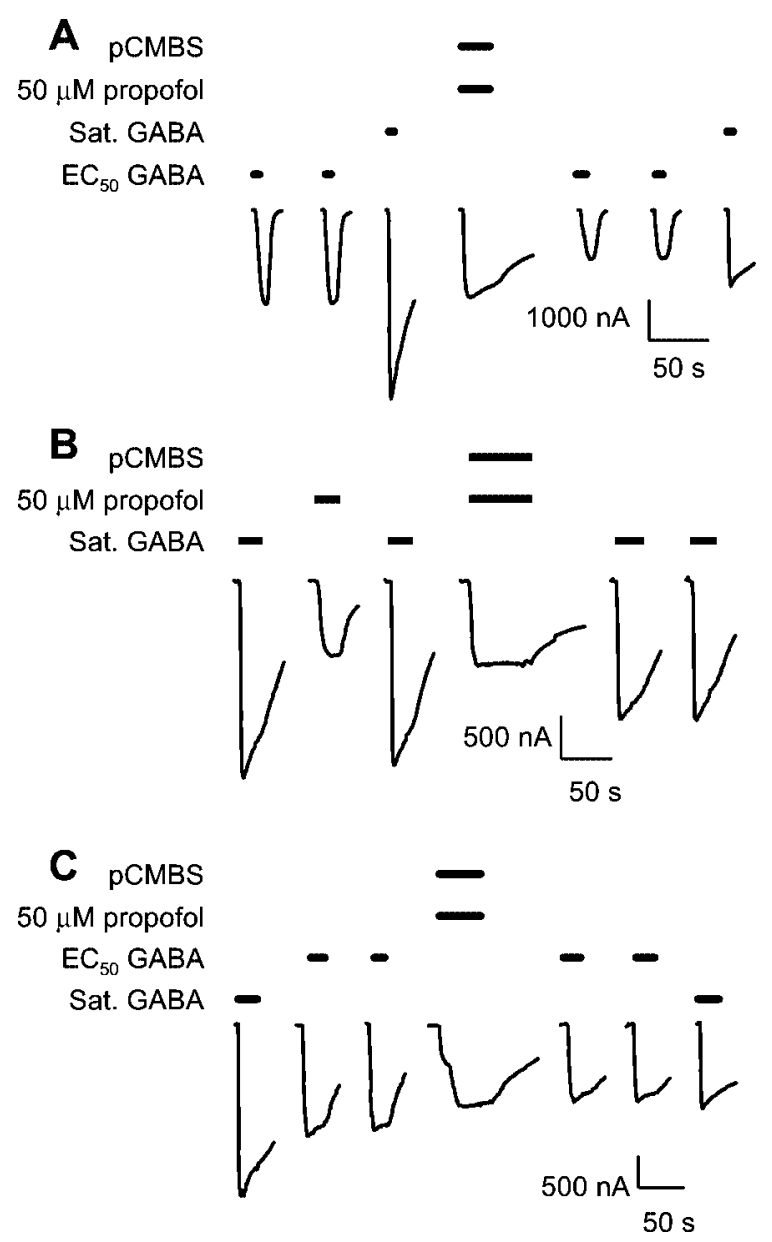

Figure 5. The effect of coapplication of $0.5 \mathrm{mM} \mathrm{pCMBS}^{-}$with $50 \mu \mathrm{M}$ propofol, a directly activating concentration, on the subsequent GABAinduced currents. Currents recorded by two-electrode voltage clamp from oocytes expressing the $\alpha_{1} \mathrm{I} 302 \mathrm{C}(A), \alpha_{1} \mathrm{E} 303 \mathrm{C}(B)$, and $\alpha_{1} \mathrm{~A} 305 \mathrm{C}(C)$ mutants. Bars above the current traces indicate the reagent applied and the duration of application. Time between current traces is 3-5 min. Holding potential, $-80 \mathrm{mV}$. Note that the subsequent GABA-induced currents evoked by both saturating and $\mathrm{EC}_{50}$ GABA concentrations are inhibited. The data in $A$ and $C$ suggest that $\mathrm{pCMBS}^{-}$modification reduced the GABA $\mathrm{EC}_{50}$.

$\mathrm{pCMBS}^{-}$irreversibly inhibited the subsequent GABA-induced currents of the mutants $\alpha_{1}$ Y294C, $\alpha_{1}$ S299C, $\alpha_{1}$ I302C, $\alpha_{1}$ E303C, and $\alpha_{1} \mathrm{~A} 305 \mathrm{C}$ (Figs. 5, 6). As described above, because $\alpha_{1} \mathrm{Y} 294 \mathrm{C}$ reacts with $\mathrm{pCMBS}^{-}$in the resting state, we measured the rate of reaction in the presence of $50 \mu \mathrm{M}$ propofol. The second order reaction rate was $118 \pm 231 \cdot \mathrm{mol}^{-1} \cdot \mathrm{sec}^{-1}(n=3)$, faster than the reaction rate in the absence of GABA, $47 \pm 8$ $1 \cdot \mathrm{mol}^{-1} \cdot \mathrm{sec}^{-1}$ (Williams and Akabas, 1999). We also measured the $\mathrm{pCMBS}^{-}$reaction rate with $\alpha_{1} \mathrm{E} 303 \mathrm{C}$ in the presence of 50 $\mu \mathrm{M}$ propofol to compare with the reaction rate in the presence of GABA. The rate in the presence of propofol was $76 \pm 9$ $1 \cdot \mathrm{mol}^{-1} \cdot \sec ^{-1}(n=5)$; significantly slower than the rate of $220 \pm 511 \cdot \mathrm{mol}^{-1} \cdot \mathrm{sec}^{-1}$ in the presence of GABA (Williams and Akabas, 1999).

We tested whether coapplication of $\mathrm{pCMBS}^{-}$with $50 \mu \mathrm{M}$ 2,6-di-tert-butylphenol, the anesthetically inactive structurally related compound, had any effect on the reactive mutants. A $50 \mu \mathrm{M}$ concentration of 2,6-di-tert-butylphenol did not induce a current in any of the mutants tested. A 1 min coapplication of $0.5 \mathrm{~mm}$

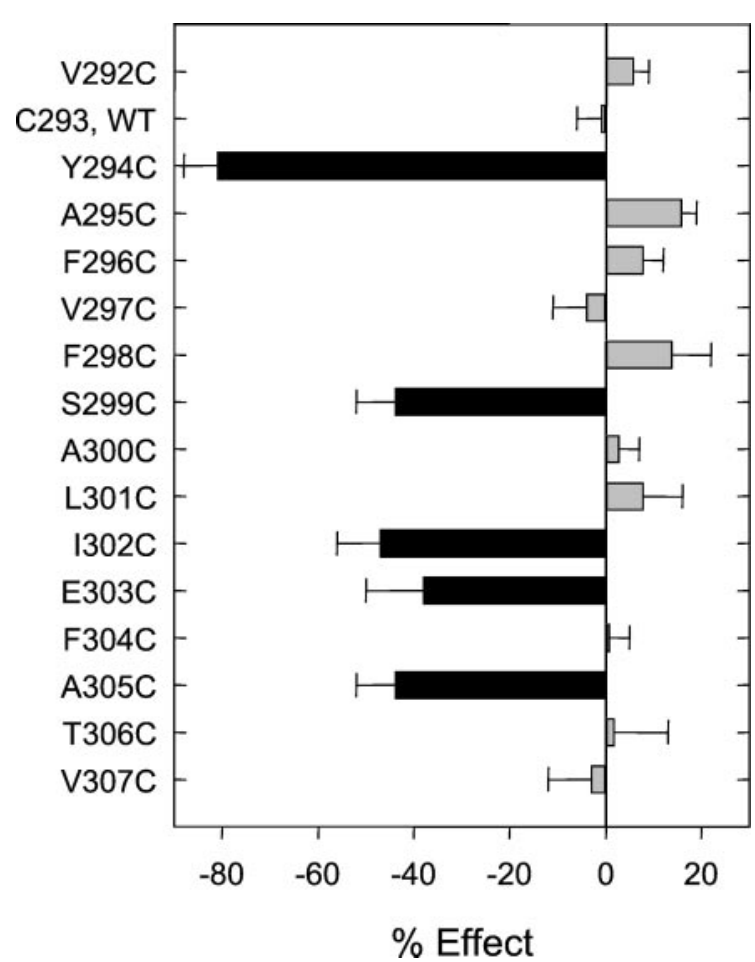

Figure 6. The irreversible effect of a $1 \mathrm{~min}$ application of $0.5 \mathrm{~mm}$ $\mathrm{pCMBS}^{-}$applied in the presence of $50 \mu \mathrm{M}$ propofol, a directly activating concentration, on subsequent GABA-induced currents of wild-type and mutant $\mathrm{GABA}_{\mathrm{A}}$ receptors. Saturating GABA concentrations were used for the test pulses. Black bars indicate effects that are statistically significantly different from the effect on wild type by a one-way ANOVA. A negative effect indicates inhibition, and a positive effect indicates potentiation of subsequent GABA currents. The mean and SEM values are shown. For each mutant, the effects on three to seven oocytes are averaged.

$\mathrm{pCMBS}^{-}$plus $50 \mu \mathrm{M}$ 2,6-di-tert-butylphenol did not inhibit the subsequent GABA-induced currents of the mutants $\alpha_{1}$ Y294C, $\alpha_{1}$ S299C, $\alpha_{1}$ I302C, $\alpha_{1}$ E303C, and $\alpha_{1}$ A305C (Fig. 4). The hydrophobicity of the reagent coapplied with $\mathrm{pCMBS}^{-}$does not seem to affect the M3 Cys-substitution mutant reactivity. Thus, we infer that the increase in the Cys mutant accessibility in the presence of an activating concentration of propofol is related to its actions as a general anesthetic.

\section{DISCUSSION}

We have shown that $\mathrm{pCMBS}^{-}$applied in the presence of a potentiating concentration of propofol reacted with a subset of M3 segment Cys-substitution mutants (Fig. 3, Table 2). pCMBS reacted with a different subset of M3 segment Cys-substitution mutants when applied with a directly activating concentration of propofol (Fig. 6, Table 2). These subsets of $\mathrm{pCMBS}^{-}$-reactive M3 segment Cys-substitution mutants are different from the residue subsets that react with $\mathrm{pCMBS}^{-}$in the resting state, i.e., in the absence of GABA, and in the GABA-bound and diazepambound states (Table 2) (Williams and Akabas, 1999, 2000). The accessibility of the M3 segment Cys-substitution mutants to reaction with $\mathrm{pCMBS}^{-}$depends on the state of the $\mathrm{GABA}_{\mathrm{A}}$ receptor. Conformational changes during gating and during drug binding appear to alter the structure surrounding the $\mathrm{GABA}_{\mathrm{A}}$ receptor M3 membrane-spanning segments. These structural changes create access pathways from the extracellular solution into the interior of the protein. This allows $\mathrm{pCMBS}^{-}$to gain 


\begin{tabular}{lcccc}
\hline $\begin{array}{l}\text { Table 2. Summary of } \boldsymbol{\alpha}_{\mathbf{1}} \text { M3 segment Cys substitution mutant } \\
\text { accessibility to pCMBS }\end{array}$ \\
reagents \\
applied in the presence of the indicated
\end{tabular}

${ }^{a}$ Symbols indicate the effect of pCMBS $^{-}$modification on the subsequent GABAinduced currents. $\downarrow$ inhibition; $\uparrow$ potentiation; nt, not tested; absence of a symbol indicates that there was no effect of $\mathrm{pCMBS}^{-}$application.

${ }^{b}$ Data from Williams and Akabas (1999).

${ }^{c}$ Data from Williams and Akabas $(2000,2001)$.

access to M3 segment Cys-substitution mutants and thus, to react (Williams and Akabas, 1999, 2000, 2001). We infer that the distinct subsets of $\mathrm{pCMBS}^{-}$-reactive Cys-substitution mutants are markers or reporters for specific states or ensembles of receptor states. A limitation of our approach is that over the time course of our experiments (tens of seconds) the channels undergo transitions between different states. Thus, we cannot know whether the $\mathrm{pCMBS}^{-}$accessibility occurs in a single state or in multiple states. (Hereafter, when we refer to a subset of residues being a reporter for a receptor state, we implicitly acknowledge that it may be for an ensemble of states.) We hypothesize that the accessibility of residues to react with $\mathrm{pCMBS}^{-}$differs in different states. Thus, the fact that different patterns of accessible residues are obtained in the presence of different drugs or agonists suggests that different drugs stabilize specific states. Therefore, we infer that each of these agonists or modulators, GABA, propofol, and diazepam, stabilize distinct states.

Several kinetic models have been proposed to account for the results of experimental studies of $\mathrm{GABA}_{\mathrm{A}}$ receptor kinetics (Weiss and Magleby, 1989; MacDonald and Twyman, 1992; Maconochie et al., 1994; Jones and Westbrook, 1995; Jones et al., 1998, 2001; Bai et al., 1999; Jayaraman et al., 1999; Burkat et al., 2001). In general these models have three nonconducting closed states (unliganded resting state, monoliganded, and diliganded), leading to at least one open conducting state. Single-channel data provides evidence for three open states (Weiss and Magleby, 1989; MacDonald and Twyman, 1992). In addition, there are other nonconducting, desensitized states. Significant rates of entry into desensitized states can occur from the diliganded closed state (Jones and Westbrook, 1995; Bai et al., 1999) and in some models from the open state as well (Burkat et al., 2001). Studies of the effects of diazepam on channel kinetics suggest that it stabilizes a singly liganded closed state, increasing the association rate for binding the first GABA molecule (Rogers et al., 1994; Lavoie and Twyman, 1996). In contrast, studies of propofol at potentiating concentrations suggest that it stabilizes a doubly liganded closed state and slows entry into fast and slow desensitized states (Bai et al., 1999). Our experiments provide structural evidence to support the results of these kinetic studies. Thus, diazepam and propofol at potentiating concentrations alter the pCMBS $^{-}$accessibility of different subsets of M3 Cys-substitution mutants. This implies that these two drugs stabilize different states.

The subset of $\mathrm{pCMBS}^{-}$-reactive residues was different in the presence of GABA and directly activating propofol. We previously suggested that reaction in the presence of GABA may be occurring in a desensitized state (Williams and Akabas, 1999). Because propofol reduces the extent of desensitization, the residues reactive in the presence of activating propofol may be more representative of the open state. Alternatively, we cannot exclude the possibility that GABA and propofol may be stabilizing different open states.

The $\mathrm{pCMBS}^{-}$-reactive residues are, at least transiently, on the water-accessible surface of the protein (Akabas et al., 1994; Karlin and Akabas, 1998). We infer this because $\mathrm{pCMBS}^{-}$reacts a thousand times faster with the ionized thiolate form of cysteine $\left(\mathrm{S}^{-}\right)$compared with the unionized thiol $(\mathrm{SH})$ (Hasinoff et al., 1971), and only cysteines on the water-accessible surface will ionize to any significant extent. Thus, a question arises regarding how an access pathway was created for $\mathrm{pCMBS}^{-}$to reach residues in the interior of the membrane-spanning domain of the protein? We previously showed that in the presence of GABA the access pathway does not appear to pass through the open channel because the $\mathrm{pCMBS}^{-}$reaction rates were not voltage dependent (Williams and Akabas, 1999). Thus, we do not think that the $\mathrm{pCMBS}^{-}$-accessible M3 residues are part of the channel lining. More likely, as the channel undergoes the conformational changes from the closed to the open to the desensitized states, spaces are formed between the membrane-spanning segments. These spaces or crevices-cavities may transiently extend up to the extracellular surface of the protein, allowing water and $\mathrm{pC}$ $\mathrm{MBS}^{-}$to enter the cavities. High-resolution protein structures indicate that cavities in the protein interior are water-filled, even if they are lined by hydrophobic residues (Yu et al., 1999). Furthermore, the dynamic motion of proteins allows the water molecules in these cavities to exchange with bulk water (Englander and Kallenbach, 1983). Thus, in the crystal structures of bacteriorhodopsin, the number of water molecules in the protein interior changes in different photocycle intermediates, suggesting that water can rapidly move into and out of the protein interior as the protein undergoes conformational changes (Dencher et al., 2000; Maeda et al., 2000; Gottschalk et al., 2001).

The formation of water-filled cavities in the membranespanning domain during channel gating may play an important role in the mechanism of general anesthetic potentiation of GABA-induced currents. Based on our results, we infer that water-accessible cavities form around the M3 segment during channel gating and modulation by diazepam and propofol (Williams and Akabas, 1999, 2000, 2001). These cavities may form as the channel-lining M2 segments rotate as part of the conformational change from the resting to the open state (Unwin, 1995; Horenstein et al., 2001). If these cavities form or enlarge transiently during activated states of the receptor, and occupation of the cavity by an anesthetic is energetically more favorable than occupation by water, then an anesthetic partitioning into the 
cavity would stabilize that state of the receptor. Anesthetics have been shown to occupy pre-existing cavities in proteins of known crystal structure (Bhattacharya et al., 2000; Eckenhoff et al., 2001; Whittington et al., 2001). Energetically favorable occupation by an anesthetic of a protein cavity that is present in the resting state or in a transient state would be expected to stabilize the structure of that protein conformational state (Tanner et al., 2001). For the $\mathrm{GABA}_{\mathrm{A}}$ receptor anesthetic occupation of cavities formed during gating would stabilize activated states of the receptor and thus may lead to the anesthetic-induced potentiation of GABAinduced currents that is observed. Consistent with this, evidence has been presented that halothane, isoflurane, and chloroform may occupy a common cavity (Jenkins et al., 2001). A binding cavity for alcohols on $\mathrm{GABA}_{\mathrm{A}}$ and glycine receptors may also exist (Wick et al., 1998). Thus, the formation of water-filled cavities in the interior of the membrane-spanning domain during channel gating may provide a molecular basis for allosteric modulation of $\mathrm{GABA}_{\mathrm{A}}$ receptors by general anesthetics.

We infer that propofol stabilizes different receptor states at potentiating and directly activating concentrations based on the observation that different subsets of M3 Cys mutants are reactive with $\mathrm{pCMBS}^{-}$in the presence of the two concentrations. This implies that there are at least two propofol binding sites on the $\mathrm{GABA}_{\mathrm{A}}$ receptor consistent with previous results (Krasowski and Harrison, 1999). The location of these sites is unknown. Unlike diazepam, the $\gamma$ subunit is not necessary for either potentiation or activation by propofol (Jones et al., 1995). Evidence has been presented that anesthetic binding sites are formed by residues near the extracellular ends of the M2 and M3 segments. Mutation of the residues $\alpha_{1}$ Ser270 (M2) and $\alpha_{1}$ Ala291 (M3) alters potentiation by volatile anesthetics (Mihic et al., 1997; Koltchine et al., 1999; Jenkins et al., 2001), whereas mutation of the aligned residues in the $\beta$ subunit alters potentiation by intravenous anesthetics (Sanna et al., 1995; Belelli et al., 1997; Moody et al., 1997; Krasowski et al., 1998). A role for the $\alpha$ subunit in intravenous anesthetic binding has also been suggested (Krasowski et al., 1997; Uchida et al., 1997; Lam and Reynolds, 1998). We observed that Cys-substitution for $\alpha_{1}$ M3 segment residues altered the extent of potentiation by $0.5 \mu \mathrm{M}$ propofol (Table 1 ). Based on this one cannot conclude that these $\alpha$ subunit residues form part of the propofol binding site and that the mutations are directly altering affinity for propofol. More likely the mutations alter the transduction process or the relative stability of various receptor states, thereby altering the efficacy of propofol (Colquhoun, 1998).

In summary, we have shown that propofol binding at both potentiating and activating concentrations induced a conformational change in the $\mathrm{GABA}_{\mathrm{A}}$ receptor membrane-spanning domain that created a pathway for water and $\mathrm{pCMBS}^{-}$to gain access to engineered Cys residues in the $\alpha_{1}$ M3 membranespanning segment. The subsets of M3 residues that were $\mathrm{pCMBS}^{-}$-reactive in the presence of potentiating and directly activating concentrations of propofol were different, and we inferred that at the different concentrations propofol stabilized two different states or ensembles of states. These states were distinct from the resting state or the GABA-bound or diazepam-bound states. The water-filled cavities that form around the M3 segment during gating may have an important role in forming the binding sites for general anesthetics and thus in the mechanism of allosteric modulation of the $\mathrm{GABA}_{\mathrm{A}}$ receptor by general anesthetics.

\section{REFERENCES}

Akabas MH, Kaufmann C, Archdeacon P, Karlin A (1994) Identification of acetylcholine receptor channel-lining residues in the entire M2 segment of the alpha subunit. Neuron 13:919-927.

Bai D, Pennefather PS, MacDonald JF, Orser BA (1999) The general anesthetic propofol slows deactivation and desensitization of GABA(A) receptors. J Neurosci 19:10635-10646.

Belelli D, Lambert JJ, Peters JA, Wafford K, Whiting PJ (1997) The interaction of the general anesthetic etomidate with the gammaaminobutyric acid type A receptor is influenced by a single amino acid. Proc Natl Acad Sci USA 94:11031-11036.

Bhattacharya AA, Curry S, Franks NP (2000) Binding of the general anesthetics propofol and halothane to human serum albumin. High resolution crystal structures. J Biol Chem 275:38731-38738.

Burkat PM, Yang J, Gingrich KJ (2001) Dominant gating governing transient GABA(A) receptor activity: a first latency and $\mathrm{Po} / \mathrm{o}$ analysis. J Neurosci 21:7026-7036.

Colquhoun D (1998) Binding, gating, affinity and efficacy: the interpretation of structure-activity relationships for agonists and of the effects of mutating receptors. Br J Pharmacol 125:924-947.

Dencher NA, Sass HJ, Buldt G (2000) Water and bacteriorhodopsin: structure, dynamics, and function. Biochim Biophys Acta 1460:192-203.

Eckenhoff RG, Pidikiti R, Reddy KS (2001) Anesthetic stabilization of protein intermediates: myoglobin and halothane. Biochemistry 40:10819-10824.

Englander SW, Kallenbach NR (1983) Hydrogen exchange and structural dynamics of proteins and nucleic acids. Q Rev Biophys 16:521-655.

Franks NP, Lieb WR (1994) Molecular and cellular mechanisms of general anaesthesia. Nature 367:607-614.

Ghansah E, Weiss DS (1999) Benzodiazepines do not modulate desensitization of recombinant alpha1beta2gamma2 GABA(A) receptors. NeuroReport 10:817-821.

Gottschalk M, Dencher NA, Halle B (2001) Microsecond exchange of internal water molecules in bacteriorhodopsin. J Mol Biol 311:605-621.

Hasinoff BB, Masden NB, Avramovic-Zikic O (1971) Kinetics of the reaction of $p$-chloromercuribenzoate with the sulfhydryl groups of glutathione, 2-mercaptoethanol, and phosphorylase b. Can J Biochem 49:742-751.

Horenstein J, Wagner DA, Czajkowski C, Akabas MH (2001) Protein mobility and GABA-induced conformational changes in GABA(A) receptor pore-lining M2 segment. Nat Neurosci 4:477-485.

Jayaraman V, Thiran S, Hess GP (1999) How fast does the gammaaminobutyric acid receptor channel open? Kinetic investigations in the microsecond time region using a laser- pulse photolysis technique. Biochemistry 38:11372-11378.

Jenkins A, Greenblatt EP, Faulkner HJ, Bertaccini E, Light A, Lin A, Andreasen A, Viner A, Trudell JR, Harrison NL (2001) Evidence for a common binding cavity for three general anesthetics within the $\mathrm{GABA}_{\mathrm{A}}$ receptor. J Neurosci 21:RC136.

Jones MV, Westbrook GL (1995) Desensitized states prolong GABA channel responses to brief agonist pulses. Neuron 15:181-191.

Jones MV, Harrison NL, Pritchett DB, Hales TG (1995) Modulation of the $\mathrm{GABA}_{\mathrm{A}}$ receptor by propofol is independent of the gamma subunit. J Pharmacol Exp Ther 274:962-968.

Jones MV, Sahara Y, Dzubay JA, Westbrook GL (1998) Defining affin-

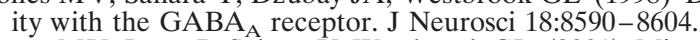

Jones MV, Jonas P, Sahara Y, Westbrook GL (2001) Microscopic kinetics and energetics distinguish $\mathrm{GABA}(\mathrm{A})$ receptor agonists from antagonists. Biophys J 81:2660-2670.

Karlin A, Akabas MH (1998) Substituted-cysteine accessibility method. Methods Enzymol 293:123-145.

Koltchine VV, Finn SE, Jenkins A, Nikolaeva N, Lin A, Harrison NL (1999) Agonist gating and isoflurane potentiation in the human gammaaminobutyric acid type A receptor determined by the volume of a second transmembrane domain residue. Mol Pharmacol 56:1087-1093.

Krasowski MD, Harrison NL (1999) General anaesthetic actions on ligand-gated ion channels. Cell Mol Life Sci 55:1278-1303.

Krasowski MD, O'Shea SM, Rick CE, Whiting PJ, Hadingham KL, Czajkowski C, Harrison NL (1997) Alpha subunit isoform influences GABA(A) receptor modulation by propofol. Neuropharmacology 36:941-949.

Krasowski MD, Koltchine VV, Rick CE, Ye Q, Finn SE, Harrison NL (1998) Propofol and other intravenous anesthetics have sites of action on the gamma-aminobutyric acid type A receptor distinct from that for isoflurane. Mol Pharmacol 53:530-538.

Krasowski MD, Jenkins A, Flood P, Kung AY, Hopfinger AJ, Harrison NL (2001) General anesthetic potencies of a series of propofol analogs correlate with potency for potentiation of gamma-aminobutyric acid (GABA) current at the GABA(A) receptor but not with lipid solubility. J Pharmacol Exp Ther 297:338-351.

Lam DW, Reynolds JN (1998) Modulatory and direct effects of propofol on recombinant GABAA receptors expressed in Xenopus oocytes: influence of alpha and gamma2 subunits. Brain Res 784:178-186. 
Lavoie AM, Twyman RE (1996) Direct evidence for diazepam modulation of $\mathrm{GABA}_{\mathrm{A}}$ receptor microscopic affinity. Neuropharmacology 35:1383-1392.

MacDonald RL, Twyman RE (1992) Kinetic properties and regulation of $\mathrm{GABA}_{\mathrm{A}}$ receptor channels. Ion Channels 3:315-343.

Maconochie DJ, Zempel JM, Steinbach JH (1994) How quickly can $\mathrm{GABA}_{\mathrm{A}}$ receptors open? Neuron 12:61-71.

Maeda A, Tomson FL, Gennis RB, Kandori H, Ebrey TG, Balashov SP (2000) Relocation of internal bound water in bacteriorhodopsin during the photoreaction of $\mathrm{M}$ at low temperatures: an FTIR study. Biochemistry 39:10154-10162.

Mihic SJ, Ye Q, Wick MJ, Koltchine VV, Krasowski MD, Finn SE, Mascia MP, Valenzuela CF, Hanson KK, Greenblatt EP, Harris RA, Harrison NL (1997) Sites of alcohol and volatile anaesthetic action on GABA(A) and glycine receptors. Nature 389:385-389.

Moody EJ, Knauer C, Granja R, Strakhova M, Skolnick P (1997) Distinct loci mediate the direct and indirect actions of the anesthetic etomidate at GABA(A) receptors. J Neurochem 69:1310-1313.

O'Shea SM, Wong LC, Harrison NL (2000) Propofol increases agonist efficacy at the GABA(A) receptor. Brain Res 852:344-348.

Rogers CJ, Twyman RE, Macdonald RL (1994) Benzodiazepine and beta-carboline regulation of single $\mathrm{GABA}_{\mathrm{A}}$ receptor channels of mouse spinal neurones in culture. J Physiol (Lond) 475:69-82.

Sanna E, Mascia MP, Klein RL, Whiting PJ, Biggio G, Harris RA (1995) Actions of the general anesthetic propofol on recombinant human GABAA receptors: influence of receptor subunits. J Pharmacol Exp Ther 274:353-360.

Tanner JW, Johansson JS, Liebman PA, Eckenhoff RG (2001) Predictability of weak binding from X-ray crystallography: inhaled anesthetics and myoglobin. Biochemistry 40:5075-5080.

Uchida I, Li L, Yang J (1997) The role of the GABA(A) receptor alpha1 subunit N-terminal extracellular domain in propofol potentiation of chloride current. Neuropharmacology 36:1611-1621.

Unwin N (1995) Acetylcholine receptor channel imaged in the open state. Nature 373:37-43.
Weiss DS, Magleby KL (1989) Gating scheme for single GABAactivated Cl- channels determined from stability plots, dwell-time distributions, and adjacent-interval durations. J Neurosci 9:1314-1324.

Whittington DA, Rosenzweig AC, Frederick CA, Lippard SJ (2001) Xenon and halogenated alkanes track putative substrate binding cavities in the soluble methane monooxygenase hydroxylase. Biochemistry 40:3476-3482.

Wick MJ, Mihic SJ, Ueno S, Mascia MP, Trudell JR, Brozowski SJ, Ye Q Harrison NL, Harris RA (1998) Mutations of gamma-aminobutyric acid and glycine receptors change alcohol cutoff: evidence for an alcohol receptor? Proc Natl Acad Sci USA 95:6504-6509.

Williams DB, Akabas MH (1999) Gamma-aminobutyric acid increases the water accessibility of M3 membrane-spanning segment residues in gamma-aminobutyric acid type A receptors. Biophys J 77:2563-2574.

Williams DB, Akabas MH (2000) Benzodiazepines induce a conformational change in the region of the gamma-aminobutyric acid type A receptor alpha(1)-subunit M3 membrane-spanning segment. Mol Pharmacol 58:1129-1136.

Williams DB, Akabas MH (2001) Evidence for distinct conformations of the two alpha(1) subunits in diazepam-bound $\mathrm{GABA}(\mathrm{A})$ receptors. Neuropharmacology 41:539-545.

Xu M, Akabas MH (1993) Amino acids lining the channel of the gamma-aminobutyric acid type A receptor identified by cysteine substitution. J Biol Chem 268:21505-21508.

Xu M, Akabas MH (1996) Identification of channel-lining residues in the M2 membrane-spanning segment of the $\mathrm{GABA}_{\mathrm{A}}$ receptor alpha1 subunit. J Gen Physiol 107:195-205.

Yamakura T, Bertaccini E, Trudell JR, Harris RA (2001) Anesthetics and ion channels: molecular models and sites of action. Annu Rev Pharmacol Toxicol 41:23-51.

Yu B, Blaber M, Gronenborn AM, Clore GM, Caspar DL (1999) Disordered water within a hydrophobic protein cavity visualized by $\mathrm{x}$ - ray crystallography. Proc Natl Acad Sci USA 96:103-108. 